\title{
Development of a Chemiluminescence Immunoassay for Serum YB-1 and its Clinical Application as a Potential Diagnostic Marker for Hepatocellular Carcinoma
}

\author{
Li Pu ${ }^{1}$, Shi Jing ${ }^{2}$, Guo Bianqin ${ }^{1}$, Liu Ping ${ }^{1}$, Liang Qindong ${ }^{1}$, Liu Chenggui ${ }^{1}$, Cheng Feng ${ }^{1}$, \\ Kuang Wenbin ${ }^{1}$, Wang Qin ${ }^{1}$, Dong Jinyu ${ }^{1}$, Xia Qianfeng ${ }^{3}$, Liu Yu ${ }^{4}$, Tu Zhiguang ${ }^{1, *}$ \\ ${ }_{2}^{1}$ Key Laboratory of Clinical Laboratory Diagnostics, College of Laboratory Medicine, Chongqing Medical University, Chongqing, China \\ ${ }_{3}^{2}$ Department of Clinical Laboratory, The First Affiliated Hospital, Chongqing Medical University, Chongqing, China \\ ${ }_{4}^{3}$ Department of Laboratory Medicine, Hainan Medical College, Hainan, China \\ ${ }^{4}$ Department of Clinical Laboratory, Chongqing Tumor Hospital, Chongqing, China \\ *Corresponding author: Tu Zhiguang, Key Laboratory of Clinical Laboratory Diagnostics, College of Laboratory Medicine, Chongqing Medical University, Chongqing, China. Tel: +86- \\ 2368485759, Fax:+86-2368485005, E-mail: tuzhiguang@yahoo.com.cn.
}

Received: November 01, 2012; Revised: January 14, 2013; Accepted: January 24, 2013

\begin{abstract}
Background: Y-box binding protein 1(YB-1) overexpression has been shown in various tumor cells including hepatocellular carcinoma (HCC); moreover, this protein can be actively secreted.

Objectives: The aim of this study was to establish a method to quantify serum YB-1 and evaluate its clinical application in the clinical diagnosis of HCC.

Patients and Methods: Recombinant YB-1 and two populations of its antibodies were prepared. A monoclonal antibody was specific to the N-terminus of YB-1 amino acids 134-160; and another was a polyclonal antibody. A sandwich-type chemiluminescence immunoassay (CLIA) was developed and evaluated. Levels of YB-1 and alpha fetoprotein (AFP) in serum samples from 105 HCC patients, 25 hepatitis B virus patients, 25 cirrhosis patients, and 50 healthy donors were detected using the established method and an AFP electrochemiluminescence kit.

Results: The developed method was linear to $150 \mu \mathrm{g} / \mathrm{L}$ of YB-1 with a minimum detection limit of $0.01 \mu \mathrm{g} / \mathrm{L}$. The average recoveries were between $93.9 \%$ and $109.0 \%$. The mean intra- and inter-assay coefficients of variation (CVs) were $4.0-4.8 \%$ and $8.2-10.2 \%$, respectively. The relationship between the concentration of diluted YB-1 and the dilution ratios gave a good linear correlation coefficient of 0.9986 . The YB-1 concentration was increased in serum of HCC patients $(33.0 \pm 23.39 \mu \mathrm{g} / \mathrm{L})$ compared to healthy individuals $(13.2 \pm 5.29 \mu \mathrm{g} / \mathrm{L}, \mathrm{P}<0.0001)$, patients with $\mathrm{HBV}(17.9 \pm 7.49 \mu \mathrm{g} / \mathrm{L}, \mathrm{P}=0.0003)$, and patients with $\mathrm{HBV}$ cirrhosis $(20.7 \pm 8.75 \mu \mathrm{g} / \mathrm{L}, \mathrm{P}<0.05)$. Moreover, the combination of YB-1 and alpha-fetoprotein had a high sensitivity (89.5\%) and reasonable specificity (62.0\%) in identifying HCC.

Conclusions:The established method has an acceptable performance in quantifying YB-1. In addition, serum YB-1 may aid in the diagnosis of HCC.
\end{abstract}

Keywords: Y-Box-Binding Protein 1; Carcinoma; Hepatocellular; Tumor Marker

\section{Background}

Hepatocellular carcinoma (HCC) is one of the lethal forms of malignant tumors with poor prognosis and difficult for early diagnosis due to the lack of reliable biomarkers. Alpha-fetoprotein (AFP), widely used for diagnosis and surveillance, shows a low diagnostic sensitivity for HCC (1). Other recently discovered markers as promising tools for HCC diagnosis, include abnormal prothromhin (APT), lens culinaris agglutinin-reactive AFP (AFP-L3) and dickkopf-1 (2,3). These markers, however, are only used for screening HCC with AFP-negative and are still under research. Y-box binding protein 1(YB-1), an oncogenic transcription/translation factor, belonging to the highly conserved cold-shock domain protein superfamily, plays pleiotropic functions in the cell cycle, such as the regulation of transcription and translation (4). YB-1 is overexpressed in many malignant cells $(5,6)$. Consider-

\section{Implication for health policy/practice/research/medical education:}

In our submitted manuscript, recombinant YB-1 and two populations of antibodies were prepared; and a rapid and sensitive sandwich-type chemiluminescence immunoassay (CLIA) was developed. The concentrations of serum YB-1 in healthy donors, hepatitis B virus patients, patients with hepatic cirrhosis and HCC patients were quantitatively measured for the first time. This revealed that serum YB-1 concentrations were significantly increased in HCC compared with control groups. Furthermore, the combination of YB-1 and alpha-fetoprotein has a high sensitivity and reasonable specificity to identify HCC. Our findings suggested that this new assay is reliable for routine clinical application, and serum YB-1 levels might be a potential routine tumor marker for screening HCC, especially when tested in parallel with alpha-fetoprotein.

Copyright @2013, Kowsar Corp.; Licensee Kowsar Ltd. This is an Open Access article distributed under the terms of the Creative Commons Attribution License(http:/ creativecommons.org/licenses/by/3.0), which permits unrestricted use, distribution, and reproduction in any medium, provided the original work is properly cited. 
able research has been conducted regarding the role of intracellular elevated levels of YB-1 mRNA and protein by RT-PCR and Western blotting in cancer progression and chemotherapy resistance. Immunohistochemical observations have demonstrated that overexpression of YB-1 occurs in a variety of cancer cells and tissues, and is involved in tumorigenesis, tumor growth, and disease progression (7-9). The cytoplasmic and predominant nuclear localization of YB-1 is consistent with the intrinsic expression of many oncogenes (7, 9-13), response to oxidative stress, and coordination of DNA excision repair (14), and has been associated with an unfavorable outcome in cancer patients $(13,15,16)$. A recent study confirmed that YB-1 can be actively secreted through a non-classical pathway in the presence of cytokines and oxidative stress (17). Furthermore, Tacke (18) reported that the active secretion of YB-1 in plasma can be detected by Western blotting, and a fragment of YB-1 (18kDa) was identified as an independent biomarker for patients with malignancy diseases. Investigating the significance of serum YB-1 levels in cancer patients is limited due to a lack of a suitable sensitive and specific quantitative detection method, which could potentially allows diversification of the relative risk profile and sensitivity to chemotherapy $(12,19)$.

\section{Objectives}

In the present study, recombinant YB-1 protein and specific YB-1 monoclonal (mAbs) and polyclonal antibodies (pAbs) were prepared. A double antibody sandwich chemiluminescence immunoassay (CLIA) method was developed to detect serum YB-1 and applied for clinical diagnosis. Moreover, the diagnostic sensitivity, specificity, and accuracy of serum YB-1 for HCC were evaluated and compared with AFP and the combination of YB-1 and alpha-fetoprotein (AFP).

\section{Patients and Methods}

\subsection{Reagents, Cell strains, and Apparatus}

Female BALB/c mice were purchased from the Animal Center of Chongqing Medical University (Chongqing, China). The origin of the myeloma cell line, SP2/0, was from the Institute of Biochemistry and Cell Biology (Chinese Academy of Sciences, Shanghai, China). The renal cancer cell line, 786-0, the breast cancer cell line, MDAMB-231, the HCC cell line, HepG2, and the non-small cell lung cancer (NSCLC) cell line, A549, were obtained from our laboratory. Goat anti-mouse IgG-horseradish peroxidase (HRP) and the Rapid ELISA Mouse mAb Isotyping Kit were obtained from Pierce (Rockford, IL, USA). Rabbit mAb to YB-1 (ab76540; Abcam, Cambridge, MA, USA). All other reagents were of analytical grade. All washing steps were carried out with an automatic plate washer (Biosci- ence, Tian Jin, China). The PETECK96-II Detection System (Bioscience) was used to read relative light units (RLU) at $450 \mathrm{~nm}$. AFP was detected using an ARCHITECT i2000sr electrochemiluminescence analyzer with an Architect AFP kit (Abbott Diagnostics, Abbott Park, IL, USA).

\subsection{Study Population and Sample Collection}

In the current study, we determined the serum YB-1 concentrations of 41 female and 64 male patients between 40 and 65 years of age (mean, 53.8 years; median, 54 years) with various stages of HCC (Table 1 ).

\begin{tabular}{cl}
\hline \multicolumn{2}{l}{ Table 1. Demographic and HCC Characteristics } \\
\hline HCC characteristics & No. $\%)$ \\
\hline Overall patients & 105 \\
Tumor status & $10(10)$ \\
T1 & $31(30)$ \\
T2 & $50(47)$ \\
T3 & $14(13)$ \\
T4 & \\
Nodal status & $24(23)$ \\
N1 & $54(51)$ \\
N2 & $27(26)$ \\
N3 & \\
Metastasis & $63(60)$ \\
M0 & $42(40)$ \\
M1 & \\
Stage & $10(10)$ \\
2 & $35(33)$ \\
3 & $43(41)$ \\
4 & $17(16)$ \\
\hline
\end{tabular}

We also determined the serum YB-1 levels of 25 ageand gender-matched hepatitis B virus (HBV)-infected patients, $25 \mathrm{HBV}$ patients with advanced stage cirrhosis diagnosed according to the results of histopathological examinations or the combined results of clinical, laboratory, and imaging examinations, and 50 healthy volunteers. All of the HCC patients were diagnosed based on histopathological findings. These subjects were all recruited from the Chongqing Tumor Hospital in China, and all subjects gave written informed consent to participate in the study. The study was approved by the Science and Ethic Committee of Chongqing Medical University and was performed in accordance with the Declaration of Helsinki. Measurement of serum YB-1 and AFP was performed in HCC patients before treatment and surgery and all control subjects. Blood samples were collected in 
vacuum blood collection tubes and centrifuged at 2500 $\mathrm{x} \mathrm{g}$ for $10 \mathrm{~min}$ at $4^{\circ} \mathrm{C}$ within $30 \mathrm{~min}$ after the formation of the blood clot. The sera aliquots were stored at $-80^{\circ} \mathrm{C}$ until analyzed.

\subsection{Recombinant Human YB-1 Protein Preparation}

\subsubsection{Amplification of the YB-1 Gene by RT-PCR}

The YB-1 cDNA coding sequence (GenBank ID: NM_004559.3) was obtained by RT-PCR using the total RNA from the human renal cancer cell line, 786-0, as a template with the following primers: ATGAGCAGCGAGGCCGAGAC; and TTACTCAGCCCCGCCCTGCT. The sequence was cloned into vector pGEX-6P-1 (Invitrogen, Carlsbad, CA, USA) and confirmed by DNA sequencing.

\subsubsection{Expression and Purification of Recombinant YB-1}

For prokaryotic expression and purification of human YB-1 (20), the recombinant plasmid was transformed into Escherichia coli strain BL21 (DE3; Novagen, Madison, WI, USA), and induced by the addition of $0.5 \mathrm{mM}$ isopropyl$\beta$-D-thiogalactoside at 20 for $6 \mathrm{~h}$. To purify the well-expressed fusion protein, $1.0 \mathrm{~g}$ of cultured cells were lysed on ice by ultrasonication and subjected to centrifugation at $20000 \mathrm{xg}$ at $4^{\circ} \mathrm{C}$ for $30 \mathrm{~min}$. The supernatants, then underwent glutathione S-transferase tag (GST-tag) affinity chromatography (Thermo Scientific, Waltham, MA, USA) according to the manufacturer's instructions. Removal of the GST-tag from the affinity-purified fusion protein was achieved by incubating $20 \mu \mathrm{g}$ of the fusion protein with 1 unit of PreScission Protease (PSP; GE Healthcare, Piscataway, NJ, USA) in PBS and $1 \mathrm{mmol} / \mathrm{L}$ DTT at $4^{\circ} \mathrm{C}$ for $24 \mathrm{~h}$, and further purification was achieved by ion exchange chromatography using an ÄKTApurifier ${ }^{\mathrm{TM}}$ Versatile FPLC purification system (GE Healthcare) to obtain highly purified YB-1 protein ( $\geq 95 \%$ ). Ultrafiltration concentration of the purified YB-1 from column eluents was performed with an Amicon Ultra-15 Centrifugal Filter Unit (Millipore, Billerica, MA, USA). The final cleaved product was analyzed by SDS-PAGE and Western blot.

\subsection{Preparation of Antibodies}

Rabbit anti-human YB-1 pAbs were prepared by injecting a rabbit subcutaneously 4 times at 2-week intervals with $2 \mathrm{mg}$ of recombinant human YB-1 emulsified with an equal volume of Freund's adjuvant. The IgG fraction of antiserum was purified by protein A sepharose column chromatography (GE Healthcare). Purified pAbs were conjugated with HRP using an EZ-Link Plus Activated Peroxidase Kit (Pierce) according to the manufacturer's coupling protocols. YB-1 mAb was prepared by immunizing mice with $100 \mu \mathrm{g}$ of recombinant YB-1 emulsified with an equal volume of complete Freund's adjuvant and subcutaneously injected into female BALB/c mice 4 times at 2-week intervals. Four days after the last booster injec- tion, spleen cells obtained from the immunized mice were fused with mouse myeloma cells (Sp2/0) in the presence of 50\% polyethylene glycol and 7.5\% DMSO (21), and cultured according to standard procedures. Hybridoma culture supernatants from 96-well plates were screened using an ELISA with recombinant YB-1 protein as the specific antigen. The positive-detected hybridoma cells were single-cells cloned five times by limited dilution. A clone was selected to yield a mAb (1-D9), which could specifically recognize YB-1 based on Western blot analysis. Ascites immunoglobulins, which were induced by injecting the 1-D9 hybridoma cells $\left(0.5 \times 10^{6}\right)$ into the peritoneal cavity of BALB/c mice, were purified with protein $G$ sepharose columns (GE Healthcare). The isotype of YB-1 mAb was identified using a Rapid ELISA Mouse mAb Isotyping Kit (Pierce) according to the manufacturer's instructions.

\subsection{Epitope Identification}

The sequence of YB-1 protein (GenBank ID: NP-004550.2) was analyzed using the DNAstar program protean (DNAstar, Madison, WI, USA). According to the predicted results of DNAstar, YB-1 proteins probably exist as 9 linear epitopes as follows: 1 (18-42aa); 2 (90-110aa); 3 (134-160aa); 4 (162-195aa); 5 (197-215aa); 6 (216-235aa); 7 (236-265aa); 8 (266-303aa); and 9 (304-324aa; Figure 1). The truncated genes (1-9) of YB-1 were obtained using the recombinant vector $\mathrm{pGEX} / \mathrm{YB} 1$ as a template with the PCR primers shown in Table 2.

The nine truncated genes of YB-1 were cloned into the vector, pGEX-6P-1, and identified by DNA sequencing. The YB-1 truncated peptides were expressed by the same procedures, as described above. The nine expressed truncated peptides were detected by Western blot analysis using the 1-D9 mAb, as described below.

\subsection{SDS-PAGE and Western Blot Analysis}

Proteins were separated with $10 \%$ SDS-PAGE, and then stained with Coomassie brilliant blue for $10 \mathrm{~min}$ at $60^{\circ} \mathrm{C}$. Protein bands were observed and scanned after de-staining in solution (40\% methanol, $7 \%$ acetic acid, and 53\% distilled water). Following separation by SDS-PAGE, the proteins were transferred to PVDF membranes. The PVDF membranes were blocked with $1 \%$ BSA in TBS containing $0.1 \%$ Tween 20 (TBST), incubated overnight at $4{ }^{\circ} \mathrm{C}$ with the primary mAb (1-D9; 1:5000), YB-1 pAbs (1:500), and rabbit monoclonal anti-YB-1 (1:10000; Abcam). HRP-conjugated goat anti-mouse or anti-rabbit IgG and the ECL system were used for detection according to the manufacturer's instructions.

\subsection{CLIA Procedure}

YB-1 in the serum sample was specifically captured by the mAb,1-D9, which was a solid phase immobilization in microtiter wells. The recombinant YB-1 was diluted with $50 \%$ newborn calf serum to generate a series of YB-1 


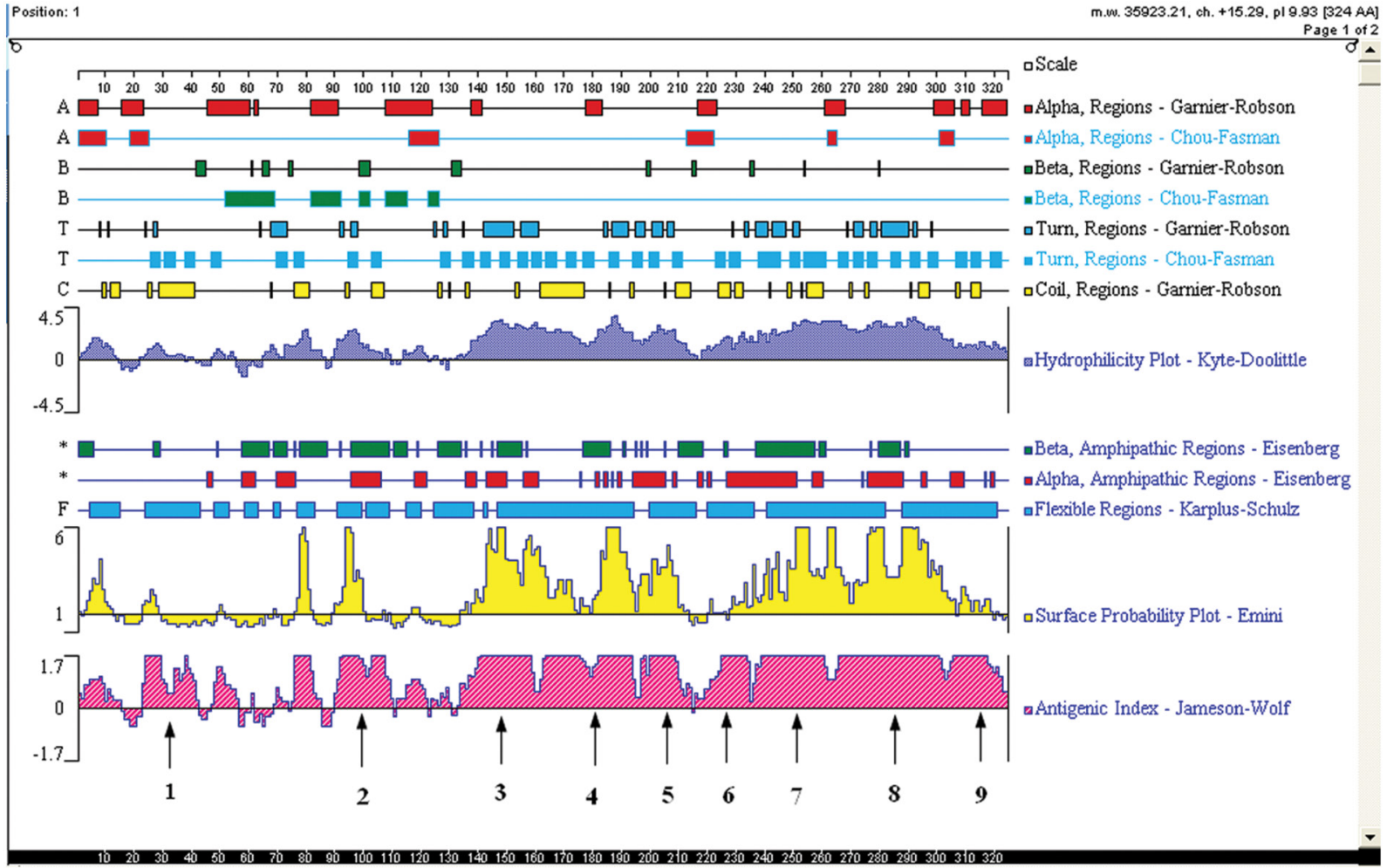

Arrows indicate the linear epitopes of YB-1 protein

Table 2. Primers for Lopping DNA Sequences of YB-1 a

\begin{tabular}{ll}
\hline Numbers 1-9 & Primers (5'-3') \\
\hline $\mathbf{1}(\mathbf{1 8 - 4 2 a a )}$ & F:GGATCCATGCCCGCCCTCAGCGCC \\
2 (90-110aa) & F:CTCGAGTTAGAGGCCGCCCGGGCC \\
& R:CTCGAGTTACTCCACAGTCTCTCC \\
$\mathbf{3}$ (134-160aa) & F:GGATCCATGCAAGGCAGTAAATAT \\
& R:CTCGAGTTATTGCTGGTAATTGCG \\
$\mathbf{4}$ (162-195aa) & F:GGATCCATGTACCAGAATAGTGAG \\
& R:CTCGAGTTAAGGTGGGAACCTTCG \\
$\mathbf{5 ( 1 9 7 - 2 1 5 a a )}$ & F:GGATCCATGTACATGCGGAGACCC \\
& R:CTCGAGTTATCCCTGCACAGGAGG \\
$\mathbf{6 ( 2 1 6 - 2 3 5 a a )}$ & F:GGATCCATGGAAGTGATGGAGGGT \\
& R:CTCGAGTTACTGCCTCACTGGTCT \\
$\mathbf{7 ( 2 3 6 - 2 6 5 a a )}$ & F:GGATCCATGAATATGTATCGGGGA \\
& R:CTCGAGTTATTCTTTATCTTCTTC \\
$\mathbf{8}$ (266-303aa) & F:GGATCCATGAATCAAGGAGATGAG \\
& R:CTCGAGTTATGTCTCTTTGCCATC \\
$\mathbf{9 ( 3 0 4 - 3 2 4 a a )}$ & F:GGATCCATGAAAGCAGCCGATCCA \\
& R:CTCGAGTTACTCAGCCCCGCCCTG \\
\hline
\end{tabular}

\footnotetext{
${ }^{\mathrm{a}}$ Underlined bases indicate restriction enzymes of
}

standards (range, 0.1-150.0 $\mu \mathrm{g} / \mathrm{L}$ ). Immunoassay procedures were performed by adding $25 \mu \mathrm{L}$ of each sample/ standards and $75 \mu \mathrm{L}$ of HRP-conjugated pAb solutions to the microtiter wells after incubating for $1 \mathrm{~h}$ at $37^{\circ} \mathrm{C}$. The wells were then washed 5 times with PBST to remove unbound antibodies. A solution/well of chemiluminescent substrate $(100 \mu \mathrm{L}$ of luminol, p-iodophenol, and urea peroxide; Sigma, St. Louis, MO, USA) was then added. The mixture was incubated for $10 \mathrm{~min}$ at room temperature in the dark, and the RLU were read at $450 \mathrm{~nm}$. The method for judging established CLIA performance, which included standard curves, linearity ranges, detection limits, recovery, intra- and inter-assay variability, and interference testing of bilirubin and hemoglobin were carried out according to the guidelines established by the Clinical Laboratory Standard Institute (22-24).

\subsection{Detection of Serum YB-1 and AFP}

The proposed CLIA was applied to quantify serum YB-1 in all enrolled subjects. AFP was also detected by an ARCHITECT i2000sr electrochemiluminescence analyzer (Abbott Diagnostics).

\subsection{Statistical analysis}

All analyses were performed with the SPSS software (ver- 
sion 16.0; SPSS, Inc., Chicago, IL, USA). Non-parametric data were compared using the Mann-Whitney U test. An independent samples t-test was performed to compare the means between the two groups. Significant differences were defined as a $\mathrm{P}<0.05$. Receiver operating characteristic (ROC) curve analysis for diagnosing HCC was performed to obtain the area under the ROC curve (AUC) of quantified serum YB-1 levels, and the diagnostic cut-off values.

Figure 2. SDS-PAGE Analysis of Recombinant YB-1 Protein Expression and Purification

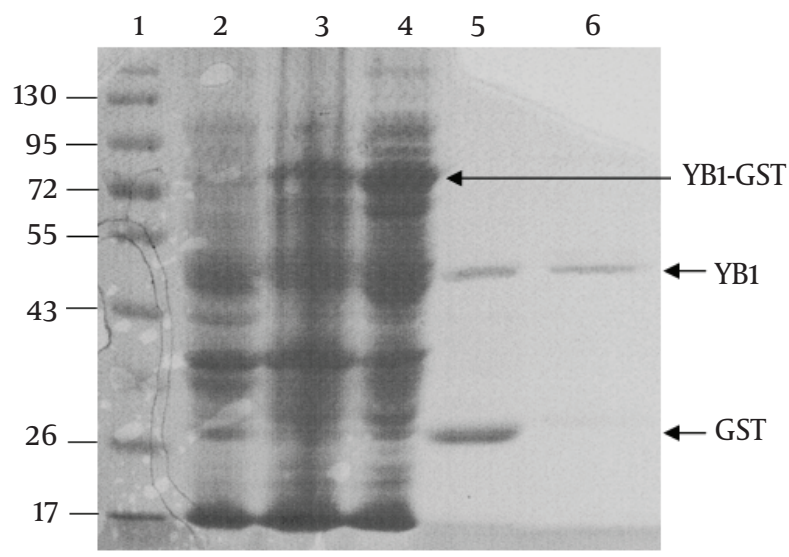

lane 1, protein marker; lane 2, negative control; lane 3, precipitation protein; lane 4, supernatant protein; lane 5, YB1-GST digested by PSP protease; lane 6, purified recombinant YB-1 protein

\section{Results}

\subsection{Expression and Purification of the YB-1 Protein}

The YB-1 coding sequence was obtained by RT-PCR. The coding sequence was inserted into the BamH and Xho sites of the vector, pGEX-6p-1, and further confirmed by DNA sequencing (data not shown). As shown in Figure. 2, the fusion protein (YB1-GST) mainly existed in the supernatants of cell lysates. Affinity purification was carried out using the GST tag of the tagged recombinant YB-1 lysates. The PSP protease recognized the GST site, and cleaved the YB1-GST with high specificity to remove the GST tag (Figure 2).

\subsection{Characterization of the Antibodies}

The mAb, 1-D9, was of the IgG1 isotope. To identify the specificity of 1-D9 and the YB-1 pAbs, Western blot analysis was performed using a commercial YB-1 mAb (Abcam) as a reference. The band corresponding to YB-1 (50 kDa) of three cancer cell lysates (breast cancer cell, MDA-MB-231; HCC cell, HepG2; and NSCLC cell, A549) and recombinant YB-1 were recognized by the commercial YB- $1 \mathrm{mAb}$, the prepared 1-D9, and the YB-1 pAbs, respectively (Figure 3).

Figure 3. Western Blot Analysis of Prepared Antibodies Recognizing YB-1 of Recombinant Protein and Tumor Cell Lysates

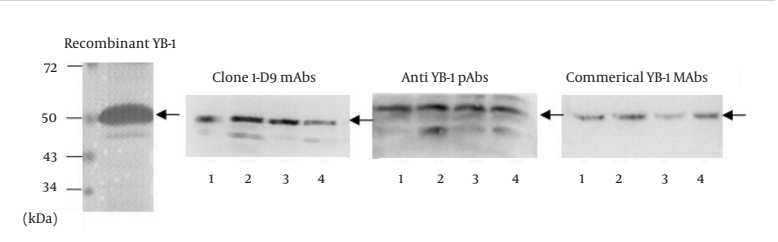

Recombinant YB-1 protein and lysates from tumor cells were immunostained with anti-YB-1 PAbs, mAbs 1-D9 and commercial YB-1 mAbs against YB-1. lane 1, recombinant YB-1; lane 2, breast cancer cell MDA-MB-231 lysates; lane 3, hepatic carcinoma cell HepG2 lysates; lane 4, non-small-cell lung cancer cell A549 lysates. Arrows indicated 50kDa YB-1.

\subsection{The Epitope of 1-D9}

Nine truncated sequences of YB-1 were obtained by PCR using the recombinant expression vector as a template (Figure 4A), and were inserted into the vector, pGEX-6p-1. To identify the epitope recognized by 1-D9, a series of YB-1 truncated peptides were expressed. As shown in Figure 4B, 1-D9 recognized the YB-1 epitope, including the number 4 amino acids between residues 134 and 160 .

\subsection{Performance of the Proposed CLIA}

This assay used $25 \mu \mathrm{L}$ serum samples and required 90 min to obtain results. The calibration curve (0.1-100.0 $\mu \mathrm{g} / \mathrm{L}$ ) of the CLIA had the following coefficient of linear correlation: $\gamma 2=0.9986[\log (\mathrm{Y})=5.8178+0.0680 \log (\mathrm{X})]$. Serial dilution of serum samples, adding YB-1 with levels of $150.0 \mu \mathrm{g} / \mathrm{L}$ produced linearity $(\gamma 2=0.999$; Figure 5$)$. The minimum detection limit was $0.1 \mu \mathrm{g} / \mathrm{L}$ (Table 3 ). Recovery experiments were conducted by adding $10.0 \mu \mathrm{g}$ of recombinant YB-1 to 10 serum samples (final concentrations ranging from 13.8 to $40.7 \mu \mathrm{g} / \mathrm{L}$ ).

The potential interference was evaluated by the addition of known increasing concentrations of hemoglobin and bilirubin. No interference was observed in the tested specimens $(\mathrm{P}>0.05)$ at moderately high hemoglobin (6.4 $\mathrm{g} / \mathrm{L})$ and bilirubin $(342 \mu \mathrm{mol} / \mathrm{L})$ concentrations (Figure 6). The range of recovery was $93.9 \%-109.0 \%(100.6 \% \pm 4.7 \%)$. The intra- and inter-assay variability was examined using three pooled serum samples with average YB-1 levels of 32.9, 15.5 , and $5.7 \mu \mathrm{g} / \mathrm{L}$. The mean intra- and inter-assay CVs were $4.0-4.8 \%$ and $8.2-10.2 \%$, respectively (Table 4 ).

4.5. Quantification of Serum YB-1 and Receiver Operating Characteristics (ROC) 
Figure 4. A) PCR Products of DNA Sequences 1-9 of YB-1 Lopping Peptides B) Hybridoma 1-D9 Was Capable of Recognizing the Truncated Peptide (134-160aa) in Western Blot Analysis

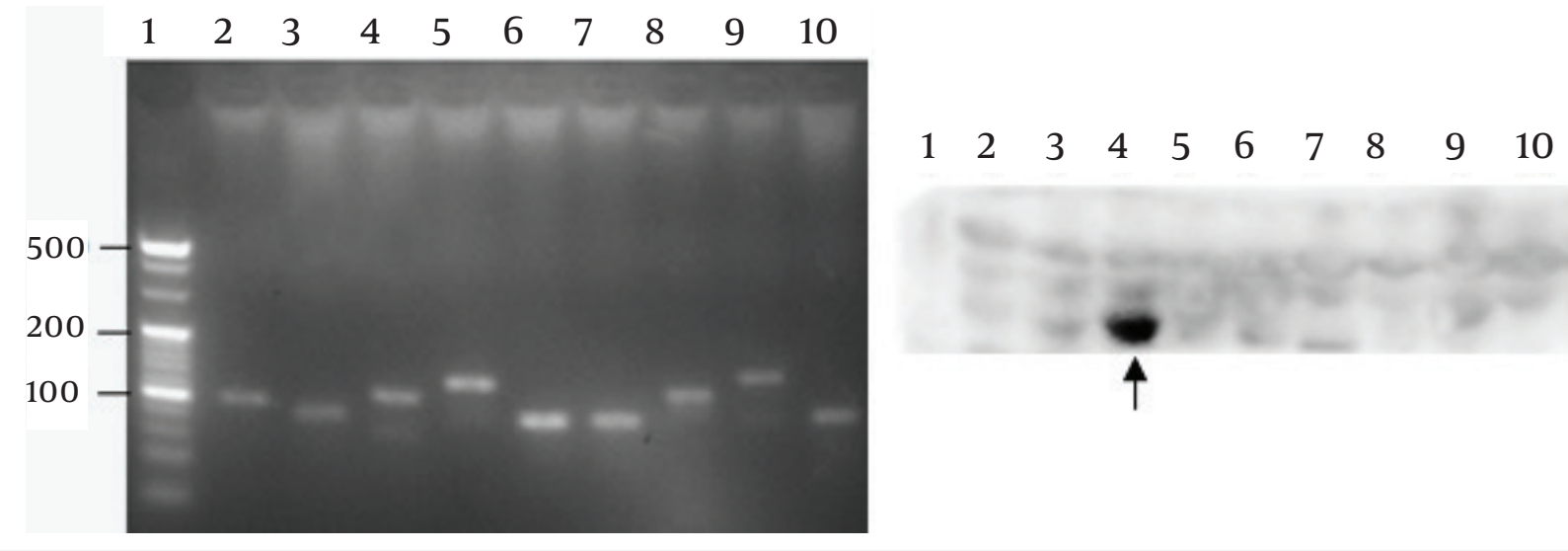

1, DNA ladder marker; 2-10, the DNA sequences of YB-1 lopping peptides 1-9lane 1, negative control; lane 2-10, YB-1 lopping peptides 1-9 negative control; lane 2-10, YB-1 lopping peptides 1-9

Figure 5. The Linearity Range of the Present Assay

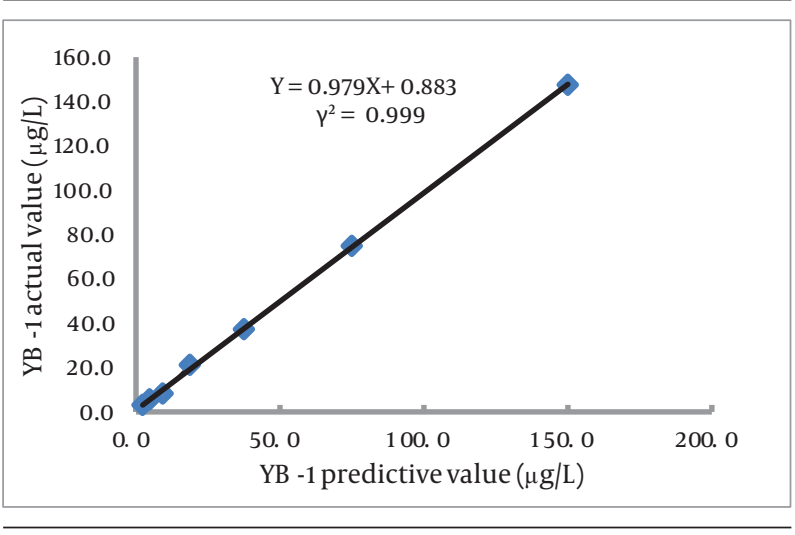

Serial dilution of samples with YB-1 levels of $150.0 \mu \mathrm{g} / \mathrm{L}$ pro duced good linearity of $\gamma 2=0.999$

\subsubsection{Serum YB-1 Concentration}

The YB-1 levels in the serum samples are shown in Fig- ure 7. With this assay, the serum levels of YB-1 in HCC was $33.0 \pm 23.39 \mu \mathrm{g} / \mathrm{L}$, which was significantly higher than the levels in samples obtained from healthy volunteers (13.2 $\pm 5.29 \mu \mathrm{g} / \mathrm{L}, \mathrm{P}<0.0001)$, patients with $\operatorname{HBV}(17.9 \pm 7.49 \mu \mathrm{g} / \mathrm{L}$, $\mathrm{P}=0.0003)$, and patients with HBV cirrhosis $(20.7 \pm 8.75$ $\mu \mathrm{g} / \mathrm{L}, \mathrm{P}<0.05)$. No relationship was observed between the serum YB-1 levels and various clinicopathologic variables, including stage, grade, and metastasis $(\mathrm{P}>0.05)$.

\begin{tabular}{lllll}
\hline \multicolumn{5}{l}{ Table 3. Minimum Limit Test of CLIA Method } \\
\hline YB-1, $\boldsymbol{\mu g} / \mathbf{L}$ & Mean $^{\mathrm{a}}$ & $S^{\mathrm{a}}$ & mean-3s $^{\mathrm{a}}$ & mean+3s $^{\mathrm{a}}$ \\
\hline $\mathbf{0}$ & 5800 & 24.1 & 5727.7 & 5872.3 \\
$\mathbf{0 . 1}$ & 10009 & 41.5 & 9884.5 & 10133.5 \\
$\mathbf{0 . 2}$ & 11408 & 23.0 & 11339.0 & 11477.0 \\
$\mathbf{0 . 3}$ & 12407 & 32.3 & 12310.1 & 12503.9 \\
$\mathbf{0 . 4}$ & 13180 & 21.1 & 13116.7 & 13243.5 \\
$\mathbf{0 . 5}$ & 14360 & 15.9 & 14312.3 & 14407.7 \\
\hline a Relative light unit (RLU) & & &
\end{tabular}

Table 4. Inter and Intra-Assay Variability for YB-1

\begin{tabular}{lllllll}
\hline $\begin{array}{l}\text { Concentration of Mixed Serum, } \\
\boldsymbol{\mu g} / \mathbf{L}\end{array}$ & Intra-Run, $\mathbf{n}=\mathbf{2 0}$ & \multicolumn{5}{c}{ Inter-Run, $\mathbf{n}=\mathbf{2 0}$} \\
& $\mathbf{X}$ & $\mathbf{S}$ & $\mathbf{C V}(\%)$ & $\mathbf{X}$ & $\mathbf{S}$ & $\mathbf{C V}(\%)$ \\
High,32.9 & 32.1 & 1.28 & 4.0 & 32.3 & 2.65 & 8.2 \\
Medium,15.5 & 15.0 & 0.68 & 4.5 & 15.2 & 1.51 & 9.9 \\
Low,5.7 & 5.2 & 0.25 & 4.8 & 5.3 & 0.54 & 10.2 \\
\hline
\end{tabular}

4.5.2. Sensitivity and Accuracy of YB-1 in Combination with AFP

The ROC plots of serum YB-1 for HCC diagnosis are pre- sented in Figure 8. The area under the ROC curve (AUC) for the YB-1 curve was 0.764 . The serum YB-1 had a sensitivity of $74.1 \%$ and a specificity of $63.0 \%$ at the cut-off value of $16.0 \mu \mathrm{g} / \mathrm{L}$ for the diagnosis of HCC. The AUC for the AFP 
curve was 0.798 . AFP had a sensitivity of $44.8 \%$ and a specificity of $93.0 \%$ at the cut-off value of $414 \mu \mathrm{g} / \mathrm{L}$. The characteristics of the diagnostic performance of serum YB-1, AFP, and YB-1+AFP for HCC are summarized in Table 5.

\section{Figure 6. Interference Test}
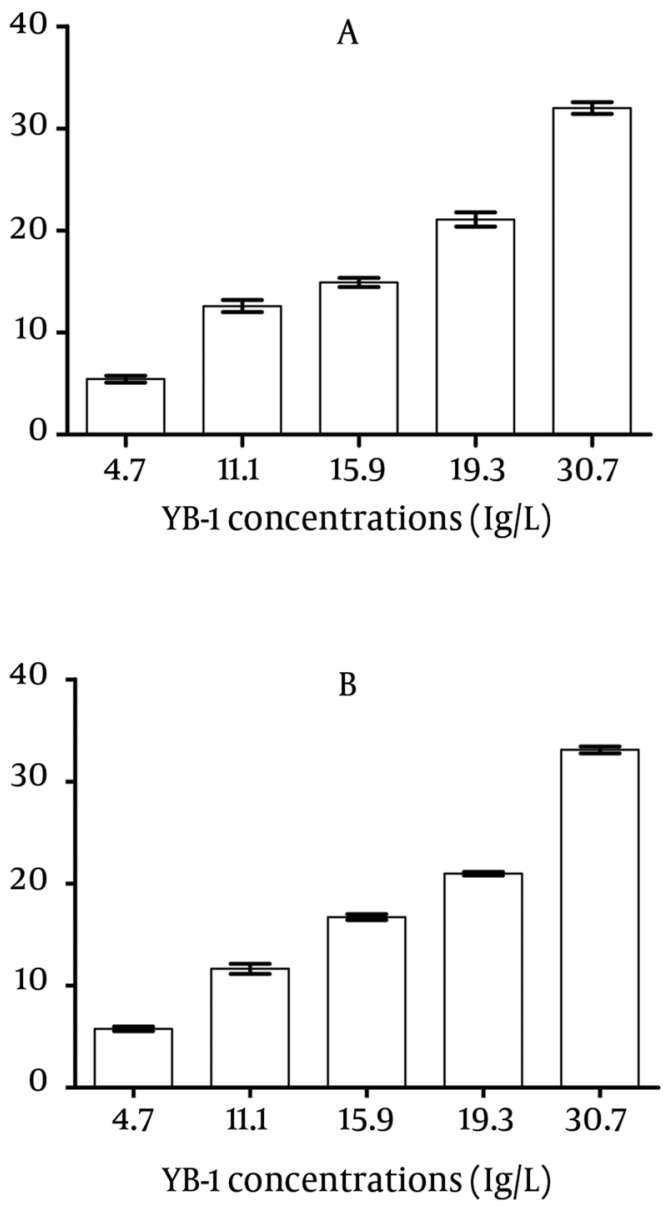

A) Interfered by hemoglobin with 1.6, 3.2 and $6.4 \mathrm{~g} / \mathrm{L}$, respectively; B) Interfered by bilirubin with 42, 85, 171 and $342 \mu \mathrm{mol} / \mathrm{L}$, respectively

AFP was more specific and less sensitive than YB-1 in diagnosing HCC; in contrast, serum YB-1 was more sensitive and less specific than AFP for the diagnosis of HCC. The sensitivity of YB-1 in combination with AFP for the diagnosis of HCC was improved to $89.5 \%$. The results suggested that the serum YB-1 levels could be applied as a screening marker for HCC; especially the combination of YB-1 and AFP exhibited a good performance for screening HCC.

\section{Discussion}

Overexpressed YB-1 have been confirmed and evaluated in cancer tissues by immunohistochemistry and RT-PCR.

Figure 7. Distribution of Serum YB-1 Concentration in Various Groups

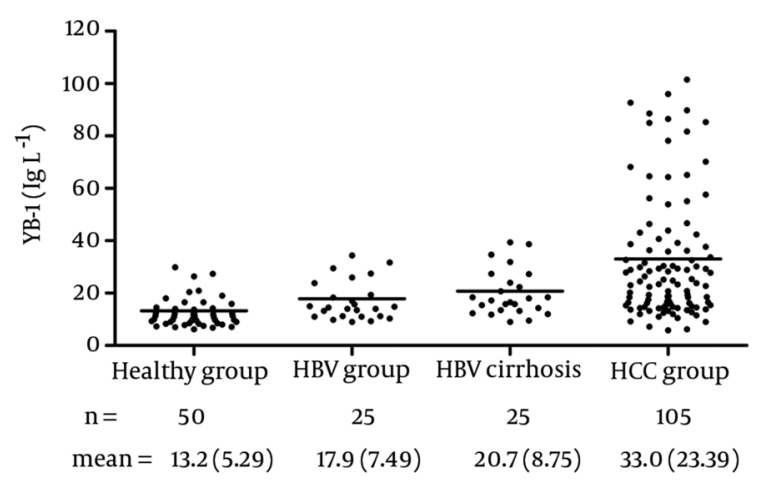

The mean values were indicated by horizontal linesAbbreviations: HBV, hepatitis B virus; HCC, hepatocellular carcinoma

A previous study showed that plasma YB-1 can be detected by Western blotting (18). However, quantifying serum YB-1 has not been available so far. In our present work, the recombinant YB-1 and YB-1 pAbs and a mAb, 1-D9, were prepared. The 1-D9-detected epitope must reside within the middle domains encompassing amino acids 134-160. A CLIA for the detection of serum YB-1 was developed based on the two prepared antibodies and a double-antibody sandwich technique. The parameters of the developed method revealed that the minimum detection was 0.1 $\mu \mathrm{g} / \mathrm{L}$, and the within- and between-run CVs were all acceptable. By quantifying the distribution of serum YB-1 in healthy donors and patients with HCC, the cut-off value of YB-1 was first determined to be $16.0 \mu \mathrm{g} / \mathrm{L}$.

Furthermore, the proposed CLIA provided a foundation for further investigation of the function and clinical significance of circulating YB-1. Major challenges of cancer in laboratory medicine relate to the diagnosis of malignant diseases and the possibility to predict the prognosis and sensitivity to chemotherapy. Regarding all these issues, the serumYB-1 may gain a prominent role, given the following: (i) YB-1 could be actively secreted (17); and (ii) extracellular YB-1 can interact with membrane receptor Notch-3 and potently up-regulate Notch target genes $(25,26)$; (iii) Notch-3 is overexpressed and promotes tumor growth in many cancers, such as HCC and lung cancer, and the suppression of Notch-3 results in loss of the malignant phenotype in vitro and in vivo (27-31); (iv) YB-1 has an oncogenic characteristic with induction of breast cancer in transgenic animals overexpressing YB-1 in the mammary gland (32); and (v) a number of reports have indicated that intracellular YB-1 up-regulates the expression of P-glycoprotein, MDR1, and the major vault protein (33-38), and its expression levels were strongly predictive 
for relapse rates and negatively correlate with disease- $\quad$ free survival $(15,16,34,39-42)$. In addition to the overexp-

\section{Figure 8. A Receiver Operating Characteristics Curve of Serum YB-1}

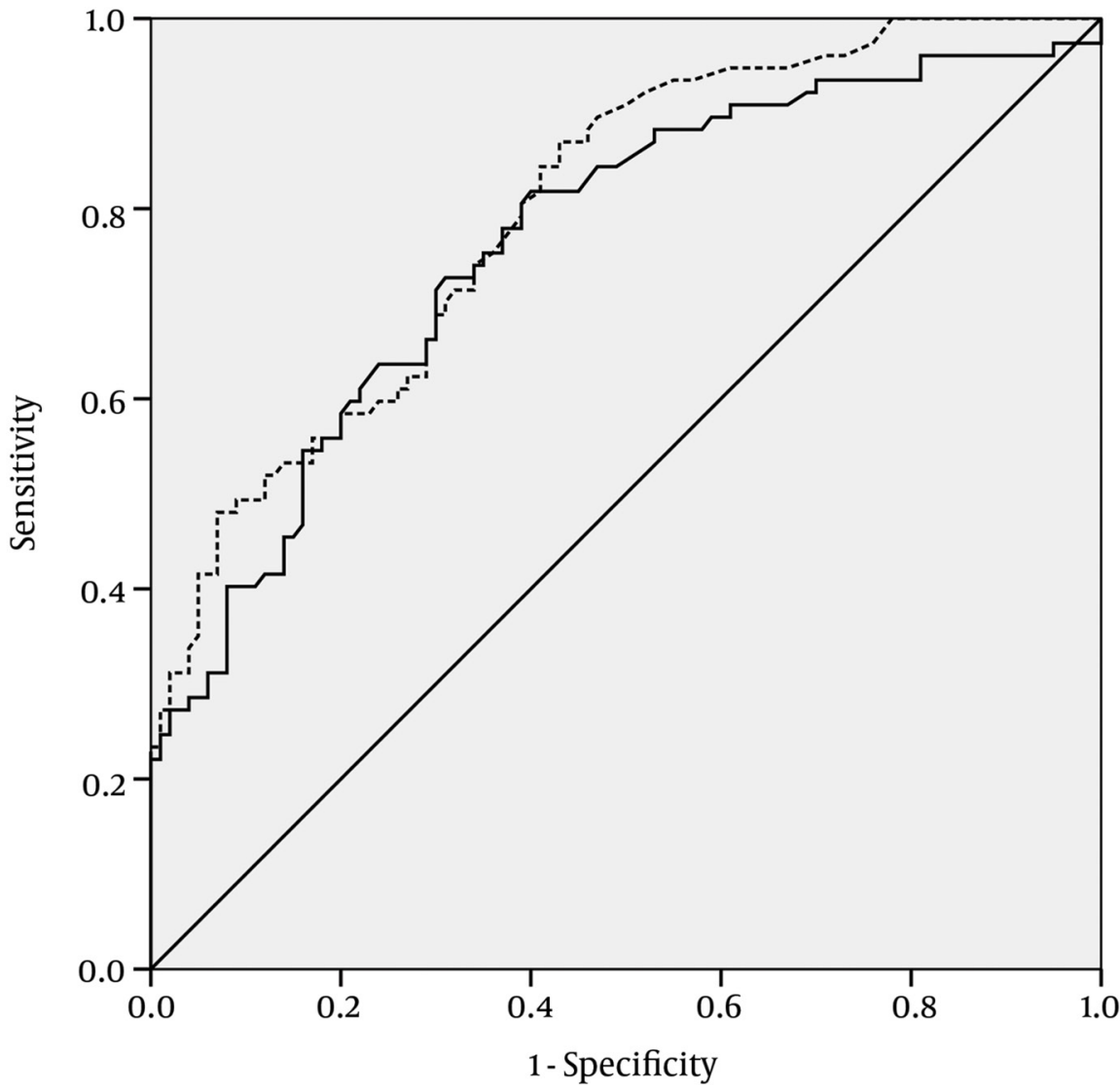

\section{Source of the Curve}

- YB1

Reference Line

Diagonal segments are produced bye ties

Sensitivity vs. specificity was calculated for all healthy individuals, HBV patients, HBV cirrhosis patients and HCC patients. The graph was drawn with 50 healthy volunteers, $25 \mathrm{HBV}$ patients, $25 \mathrm{HBV}$ cirrhosis and $105 \mathrm{HCC}$ patients.

Table 5. Diagnostic Performance of Serum YB-1, AFP and YB-1+AFP for HCC

\begin{tabular}{|c|c|c|c|c|c|c|c|c|}
\hline $\begin{array}{l}\text { Tumor } \\
\text { Marker }\end{array}$ & $\begin{array}{l}\text { Cut-Off Value, } \\
\mu \mathrm{g} / \mathrm{L}\end{array}$ & $\begin{array}{l}\text { HCC Pa- } \\
\text { tients }\end{array}$ & & $\begin{array}{l}\text { Controls, HBV + HBV } \\
\text { Cirrhosis + Healthy }\end{array}$ & & $\begin{array}{l}\text { Sensitiv- } \\
\text { ity, } \%^{\mathrm{a}}\end{array}$ & $\begin{array}{l}\text { Specific- } \\
\text { ity, \%b }\end{array}$ & $\begin{array}{l}\text { Accu- } \\
\text { racy, \% }\end{array}$ \\
\hline & & Cases & Positive & Cases & Positive & & & \\
\hline YB-1 ${ }^{d}$ & 16.0 & 105 & 80 & 100 & 37 & 74.1 & 63.0 & 69.8 \\
\hline AFP & 414 & 105 & 47 & 100 & 7 & 44.8 & 93.0 & 68.3 \\
\hline YB-1+AFP & ibid & 105 & 94 & 100 & 38 & 89.5 & 62.0 & 76.1 \\
\hline
\end{tabular}

a Sensitivity $=\mathrm{TP} /(\mathrm{TP}+\mathrm{FN})$, where $\mathrm{TP}=$ true positive, $\mathrm{FN}=$ false negative

$\mathrm{b}_{\text {Specificity }}=\mathrm{TN} /(\mathrm{TN}+\mathrm{FP})$, where $\mathrm{TN}=$ true negative, $\mathrm{FP}=$ false positive

${ }^{c}$ Accuracy $=(\mathrm{TP}+\mathrm{TN}) /(\mathrm{TP}+\mathrm{FP}+\mathrm{TN}+\mathrm{FN})$

d Abbreviations: AFP, alpha-fetoprotein; HCC, hepatocellular carcinoma

-ression of cytoplasm YB-1 and nuclear translocalization of phosphorylated YB-1 as prognostic and chemoresistance markers in several human malignancies based on immunohistochemistry $(7,9-11,13,43,44)$, a recent study (18) described the presence of YB-1 in the serum of patients with malignancies and healthy individuals by Western blotting, and found that YB-1 protein complexes (molecular sizes $>150,50$, and $30 \mathrm{kDa}$ ) were present in plasma samples, including healthy donors and patients with various cancers, such as HCC and rectal cancer. Our 
data showed that levels of serum YB-1 in HCC was significantly higher than the 3 control groups, and had good sensitivity (74.1\%) for the diagnosis of HCC. In contrast, AFP, the standard biomarker for HCC (1), had less sensitivity (44.8\%), but higher specificity (93.0\%). However, serum YB-1 combined with AFP showed higher sensitivity and diagnosed $89.5 \%$ of the HCC patients. It is proposed that the combination of YB- 1 and AFP can be used in parallel for screening high-risk patient populations with HCC because of the good sensitivity. Negative results for YB-1 and AFP, or AFP alone, would suggest that HCC is unlikely, but a positive YB-1 (which would likely occur with a positive AFP) would make the disease highly probable. A combination of our findings and the established unique role in tumor biology suggests that serum YB-1 levels might be a potential routine tumor marker for HCC. Furthermore, the serum YB-1 quantitative assay has the advantage of being less invasive and more accurate. Because of the relative small patient number, we did not find a statistically significant correlation between the serum YB-1 levels and different stages or metastasis of HCC patients. For this purpose, a large confirmative meta-analysis on HCC cohorts will be necessary. Further investigation is valuable on whether serum YB-1 level is an aid in the diagnosis of other cancers. In conclusion, we have successfully prepared a recombinant YB-1 protein and specific antibodies. A double antibody sandwich CLIA has been developed for quantifying serum YB-1, and applied for detecting YB-1 levels in healthy individuals, and patients with HBV, HBV cirrhosis, and HCC. Our results have shown that YB-1 could distinguish patients with HCC from healthy volunteers and patients with other liver diseases. Moreover, parallel combination of YB-1 and AFP can improve the diagnostic performance compared with YB-1 or AFP alone. In addition, the YB-1 antibodies and the established CLIA method may be of importance for investigating the function of circulating YB-1, and the prospective study to validate circulating YB-1 as a chemoresistance and prognostic marker in cancer patients.

\section{Acknowledgements}

This work was supported by a grant from the National Natural Science Foundation of China. Grant No.30872417. The authors thank Dr Xu Jie for the help in statistical advices.

\section{Authors' Contribution}

Li Pu and Tu Zhiguang had full access to all of the data in the study and take responsibility for the integrity of the data and the accuracy of the data analysis. Tu Zhiguang and Li Pu, Shi Jing participated in Study concept and design. Liu Ping, Kuang Wenbin, Wang Qin, and Dong Jinyu participated in Acquisition of data. Analysis and interpretation of data was done by Li Pu, Tu Zhiguang, Xia Qianfeng, Liu Chenggui, and Liang Qindong. Li Pu, Tu Zhiguang,and Shi Jing contributed in Drafting of the manuscript. Li Pu, Shi Jing,and Liu Chenggui, Cheng Feng performed the Statistical analysis.

\section{Financial Disclosure}

None reported.

\section{Funding Support}

The National Natural Science Foundation of China (No. 30872417).

\section{References}

1. Diamandis EP, Hoffman BR, Sturgeon CM. National Academy of Clinical Biochemistry Laboratory Medicine Practice Guidelines for the Use of Tumor Markers. Clin Chem. 2008;54(11):1935-9.

2. Bertino G, Ardiri A, Malaguarnera M, Malaguarnera G, Bertino N, Calvagno GS. Hepatocellualar carcinoma serum markers. Semin Oncol. 2012;39(4):410-33.

3. Shen Q, Fan J, Yang XR, Tan Y, Zhao W, Xu Y, et al. Serum DKK1 as a protein biomarker for the diagnosis of hepatocellular carcinoma: a large-scale, multicentre study. Lancet Oncol. 2012;13(8):81726.

4. Kohno K, Izumi H, Uchiumi T, Ashizuka M, Kuwano M. The pleiotropic functions of the Y-box-binding protein, YB-1. Bioessays. 2003;25(7):691-8.

5. En-Nia A, Yilmaz E, Klinge U, Lovett DH, Stefanidis I, Mertens PR. Transcription factor YB-1 mediates DNA polymerase alpha gene expression. J Biol Chem. 2005;280(9):7702-11.

6. Wu J, Lee C, Yokom D, Jiang H, Cheang MC, Yorida E, et al. Disruption of the Y-box binding protein-1 results in suppression of the epidermal growth factor receptor and HER-2. Cancer Res. 2006;66(9):4872-9.

7. Tay WL, Yip GW, Tan PH, Matsumoto K, Yeo R, Ng TP, et al. Y-Boxbinding protein-1 is a promising predictive marker of radioresistance and chemoradioresistance in nasopharyngeal cancer. Mod Pathol.2009;22(2):282-90.

8. Wachowiak R, Thieltges S, Rawnaq T, Kaifi JT, Fiegel H, Metzger R, et al. Y-box-binding protein-1 is a potential novel tumour marker for neuroblastoma. Anticancer Res. 2010;30(4):1239-42.

9. Kuwano M, Oda Y, Izumi H, Yang SJ, Uchiumi T, Iwamoto Y, et al The role of nuclear Y-box binding protein 1 as a global marker in drug resistance. Mol Cancer Ther. 2004;3(11):1485-92.

10. Bargou RC, Jurchott K, Wagener C, Bergmann S, Metzner S, Bommert $\mathrm{K}$, et al. Nuclear localization and increased levels of transcription factor YB-1 in primary human breast cancers are associated with intrinsic MDR1 gene expression. Nat Med. 1997;3(4):447-50.

11. Dhillon J, Astanehe A, Lee C, Fotovati A, Hu K, Dunn SE. The expression of activated Y-box binding protein-1 serine 102 mediates trastuzumab resistance in breast cancer cells by increasing CD44+ cells. Oncogene. 2010;29(47):6294-300.

12. Janz M, Harbeck N, Dettmar P, Berger U, Schmidt A, Jurchott K, et al. Y-box factor YB-1 predicts drug resistance and patient outcome in breast cancer independent of clinically relevant tumor biologic factors HER2, uPA and PAI-1. Int J Cancer. 2002;97(3):27882.

13. Shibahara K, Sugio K, Osaki T, Uchiumi T, Maehara Y, Kohno K, et al. Nuclear expression of the Y-box binding protein, YB-1, as a novel marker of disease progression in non-small cell lung cancer. Clin Cancer Res. 2001;7(10):3151-5.

14. Das S, Chattopadhyay R, Bhakat KK, Boldogh I, Kohno K, Prasad $\mathrm{R}$, et al. Stimulation of NEIL2-mediated oxidized base excision repair via YB-1 interaction during oxidative stress. J Biol Chem. 2007;282(39):28474-84.

15. Shiota M, Zoubeidi A, Kumano M, Beraldi E, Naito S, Nelson CC, et al. Clusterin is a critical downstream mediator of stressinduced YB-1 transactivation in prostate cancer. Mol Cancer Res. 2011;9(12):1755-66.

16. Szczuraszek K, Halon A, Materna V, Mazur G, Wrobel T, Kulicz- 
kowski K, et al. Elevated YB-1 expression is a new unfavorable prognostic factor in non-Hodgkin's lymphomas. Anticancer Res. 2011;31(9):2963-70.

17. Frye BC, Halfter S, Djudjaj S, Muehlenberg P, Weber S, Raffetseder $\mathrm{U}$, et al. Y-box protein-1 is actively secreted through a non-classical pathway and acts as an extracellular mitogen. EMBO Rep. 2009;10(7):783-9.

18. Tacke F, Kanig N, En-Nia A, Kaehne T, Eberhardt CS, Shpacovitch $\mathrm{V}$, et al. Y-box protein-1/p18 fragment identifies malignancies in patients with chronic liver disease. BMC Cancer. 2011;11:185.

19. Kuwano M, Uchiumi T, Hayakawa H, Ono M, Wada M, Izumi H, et al. The basic and clinical implications of ABC transporters, $\mathrm{Y}$ box-binding protein-1 (YB-1) and angiogenesis-related factors in human malignancies. Cancer Sci. 2003;94(1):9-14.

20. Graslund S, Nordlund P, Weigelt J, Hallberg BM, Bray J, Gileadi $\mathrm{O}$, et al. Protein production and purification. Nat Methods. 2008;5(2):135-46.

21. Norwood TH, Zeigler CJ, Martin GM. Dimethyl sulfoxide enhances polyethylene glycol-mediated somatic cell fusion. Somatic Cell Genet. 1976;2(3):263-70.

22. Powers DM. Interference Testing in Clinical Chemistry: Approved Guideline. 2002.

23. Tholen DW. Evaluation of the Linearity of Quantitative Measurement Procedures: A Statistical Approach, Approved Guideline. 2003.

24. Tholen DW. Evaluation of Precision Performance of Quantitative Measurement Methods: Approved Guideline. 2004

25. Raffetseder U, Rauen T, Boor P, Ostendorf T, Hanssen L, Floege J, et al. Extracellular YB-1 blockade in experimental nephritis upregulates Notch-3 receptor expression and signaling. Nephron Exp Nephrol. 2011;118(4):e100-8.

26. Rauen T, Raffetseder U, Frye BC, Djudjaj S, Muhlenberg PJ, Eitner F, et al. YB-1 acts as a ligand for Notch-3 receptors and modulates receptor activation. J Biol Chem. 2009;284(39):26928-40.

27. Giovannini C, Gramantieri L, Chieco P, Minguzzi M, Lago F, Pianetti S, et al. Selective ablation of Notch3 in HCC enhances doxorubicin's death promoting effect by a p53 dependent mechanism. J Hepatol. 2009;50(5):969-79.

28. Giovannini C, Lacchini M, Gramantieri L, Chieco P, Bolondi L. Notch3 intracellular domain accumulates in HepG2 cell line. An ticancer Res. 2006;26(3A):2123-7.

29. Haruki N, Kawaguchi KS, Eichenberger S, Massion PP, Olson S, Gonzalez A, et al. Dominant-negative Notch3 receptor inhibits mitogen-activated protein kinase pathway and the growth of human lung cancers. Cancer Res. 2005;65(9):3555-61.

30. Konishi J, Kawaguchi KS, Vo H, Haruki N, Gonzalez A, Carbone DP, et al. Gamma-secretase inhibitor prevents Notch3 activation and reduces proliferation in human lung cancers. Cancer Res. 2007;67(17):8051-7.

31. Serafin V, Persano L, Moserle L, Esposito G, Ghisi M, Curtarello M, et al. Notch3 signalling promotes tumour growth in colorectal cancer. J Pathol. 2011;224(4):448-60.

32. Bergmann S, Royer-Pokora B, Fietze E, Jurchott K, Hildebrandt B Trost D, et al. YB-1 provokes breast cancer through the induction of chromosomal instability that emerges from mitotic failure and centrosome amplification. Cancer Res. 2005;65(10):4078-87.

33. Gimenez-Bonafe P, Fedoruk MN, Whitmore TG, Akbari M, Ralph
JL, Ettinger S, et al. YB-1 is upregulated during prostate cancer tumor progression and increases P-glycoprotein activity. Prostate 2004;59(3):337-49.

34. Huang X, Ushijima K, Komai K, Takemoto Y, Motoshima S, Kamura T, et al. Co-expression of Y box-binding protein-1 and P-glycoprotein as a prognostic marker for survival in epithelial ovarian cancer. Gynecol Oncol. 2004;93(2):287-91.

35. Oda Y, Sakamoto A, Shinohara N, Ohga T, Uchiumi T, Kohno K, et al. Nuclear expression of YB-1 protein correlates with P-glycoprotein expression in human osteosarcoma. Clin Cancer Res. 1998;4(9):2273-7.

36. Saji H, Toi M, Saji S, Koike M, Kohno K, Kuwano M. Nuclear expression of YB-1 protein correlates with P-glycoprotein expression in human breast carcinoma. Cancer Lett. 2003;190(2):191-7.

37. Yang JY, Ha SA, Yang YS, Kim JW. p-Glycoprotein ABCB5 and YB-1 expression plays a role in increased heterogeneity of breast cancer cells: correlations with cell fusion and doxorubicin resistance. BMC Cancer. 2010;10:388.

38. Yasen M, Kajino K, Kano S, Tobita H, Yamamoto J, Uchiumi T, et al. The up-regulation of Y-box binding proteins (DNA binding protein A and Y-box binding protein-1) as prognostic markers of hepatocellular carcinoma. Clin Cancer Res. 2005;11(20):7354-61.

39. Habibi G, Leung S, Law JH, Gelmon K, Masoudi H, Turbin D, et al. Redefining prognostic factors for breast cancer: YB-1 is a stronger predictor of relapse and disease-specific survival than estrogen receptor or HER-2 across all tumor subtypes. Breast Cancer Res. 2008;10(5):R86.

40. Huang J, Tan PH, Li KB, Matsumoto K, Tsujimoto M, Bay BH. Y-box binding protein, YB-1, as a marker of tumor aggressiveness and response to adjuvant chemotherapy in breast cancer. Int J Oncol. 2005;26(3):607-13.

41. Jurchott K, Kuban RJ, Krech T, Bluthgen N, Stein U, Walther W, et al. Identification of Y-box binding protein 1 as a core regulator of MEK/ERK pathway-dependent gene signatures in colorectal cancer cells. PLoS Genet. 2010;6(12).

42. To K, Zhao Y, Jiang $\mathrm{H}$, Hu K, Wang M, Wu J, et al. The phosphoinositide-dependent kinase-1 inhibitor 2-amino-N-[4-[5-(2phenanthrenyl)-3-(trifluoromethyl)-1H-pyrazol-1-yl]phenyl]-ace tamide (OSU-03012) prevents Y-box binding protein-1 from inducing epidermal growth factor receptor. Mol Pharmacol. 2007;72(3):641-52.

43. Chaudhary PM, Roninson IB. Induction of multidrug resistance in human cells by transient exposure to different chemotherapeutic drugs. J Natl Cancer Inst. 1993;85(8):632-9.

44. Gluz O, Mengele K, Schmitt M, Kates R, Diallo-Danebrock R, Neff F, et al. Y-box-binding protein YB-1 identifies high-risk patients with primary breast cancer benefiting from rapidly cycled tandem high-dose adjuvant chemotherapy. JClin Oncol. 2009;27(36):614451.

Please cite this paper as: Li P, Shi J, Guo B, Liu P, Liang Q, Liu C, et al. Development of a Chemiluminescence Immunoassay for Serum YB-1 and its Clinical Application as a Potential Diagnostic Marker for Hepatocellular Carcinoma. Hepat Mon. 2013;13(7):e8918. DOI: 10.5812/hepatmon.8918 